\title{
Direct Carbon-Carbon Bond Formation via Soft Enolization: A Biomimetic Asymmetric Mannich Reaction of Phenylacetate Thioesters
}

2010

Vol. 12, No. 15 $3376-3379$

\author{
Mark C. Kohler, Julianne M. Yost, Michelle R. Garnsey, and Don M. Coltart*
}

Department of Chemistry, Duke University, Durham, North Carolina 27708

don.coltart@duke.edu

Received May 23, 2010

\section{ABSTRACT}
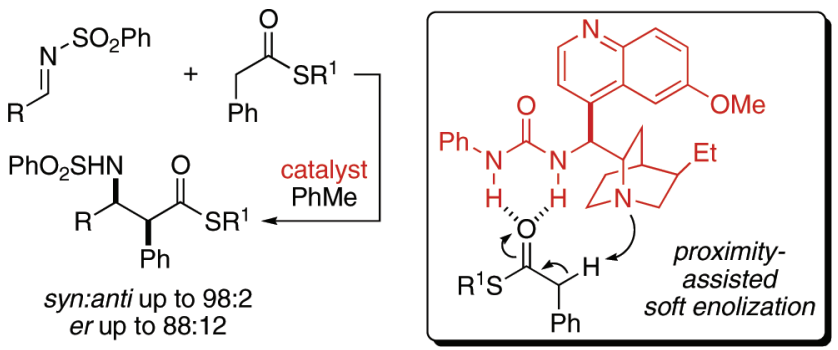

An asymmetric Mannich reaction of phenylacetate thioesters and sulfonylimines using cinchona alkaloid-based amino (thio)urea catalysts is reported that employs proximity-assisted soft enolization. This approach to enolization is based on the cooperative action of a carbonylactivating hydrogen bonding (thio)urea moiety and an amine base contained within a single catalytic entity to facilitate intracomplex deprotonation. Significantly, this allows thioesters over a range of acidity to react efficiently, thereby opening the door to the development of a general mode of enolization-based organocatalysis of monocarboxylic acid derivatives.

Soft enolization ${ }^{1,2}$ provides a mild and operationally simple approach to the deprotonation of certain types of monocarbonyl compounds. In contrast to hard enolization, wherein deprotonation is achieved irreversibly using a very strong base such as LDA, soft enolization occurs when a relatively weak amine base and a carbonyl activating component act in concert to effect reversible deprotonation. We have been investigating this mode of enolization with thioesters in direct carbon-carbon bond formation using $\mathrm{Mg}^{2+}$ Lewis acids for carbonyl activation. ${ }^{2}$ Our inspiration for studying thioesters

(1) For pioneering examples of soft enolization, see: Rathke, M. W.; Cowan, P. J. J. Org. Chem. 1985, 50, 2622-2624. Rathke, M. W.; Nowak, M. J. Org. Chem. 1985, 50, 2624-2626. Tirpak, R. E.; Olsen, R. S.; Rathke, M. W. J. Org. Chem. 1985, 50, 4877-4879.

(2) (a) Yost, J. M.; Garnsey, M. R.; Kohler, M. C.; Coltart, D. M. Synthesis 2008, 56-58. (b) Zhou, G.; Lim, D.; Coltart, D. M. Org. Lett. 2008, 10, 3809-3812. (c) Zhou, G.; Yost, J. M.; Coltart, D. M. Synthesis 2007, 478-482. (d) Yost, J. M.; Zhou, G.; Coltart, D. M. Org. Lett. 2006, $8,1503-1506$. in this context stems from the way in which enolization occurs in the enzyme citrate synthase. ${ }^{3}$ Thioester activation in citrate synthase is achieved by hydrogen bonding rather than Lewis-acid coordination (Scheme 1a). While a weaker form of carbonyl activation, it is sufficient to allow deprotonation by a weakly basic carboxylate group. ${ }^{4}$ This is likely due in large part to the proximity effects imparted to the system as a result of the close spatial arrangement of the

(3) (a) Mulholland, A. J.; Lyne, P. D.; Karplus, M. J. Am. Chem. Soc. 2000, 122, 534-535. (b) Usher, K. C.; Remington, S. J.; Martin, D. P.; Drueckhammer, D. G. Biochem. 1994, 33, 7753-7759. (c) Wiegand, G.; Remington, S. J. Ann. Rev. Biophys. Chem. 1986, 15, 97-117.

(4) The effect of hydrogen bonding on thioester acidity has been shown for acetyl-CoA dehydrogenase. See: Rudik, I.; Thorpe, C. Arch. Biochem. Biophys. 2001, 392, 341-348.

(5) For accounts of proximity accelerated intramolecular transformations in general, see: (a) Menger, F. M. Acc. Chem. Res. 1985, 18, 128-134. (b) Kirby, A. Adv. Phys. Org. Chem. 1980, 17, 183-278. (c) Page, M. I. Chem. Soc. Rev. 1973, 2, 295-323. (d) Page, M.; Jencks, W. Proc. Natl. Acad. Sci. U.S.A. 1971, 68, 1678-1683. (e) Capon, B. Q. Rev., Chem. Soc. 1964, $18,45-111$. 
Scheme 1. (a) Citrate Synthase Reaction and (b) Proposed Biomimetic Asymmetric Mannich Reaction
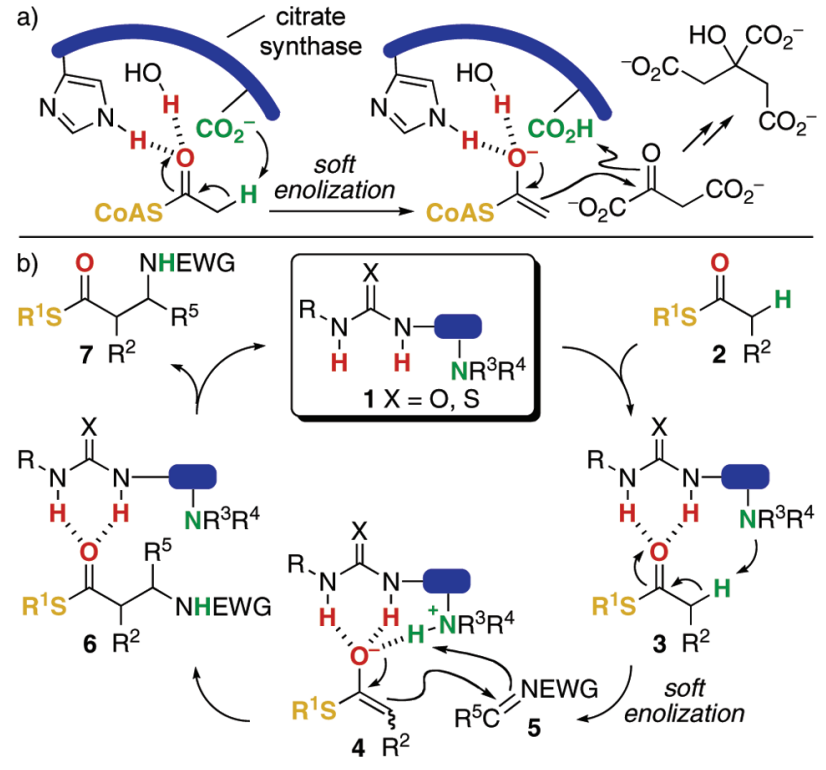

base and the thioester $\alpha$-protons. ${ }^{5,6}$ As we have previously suggested, ${ }^{2}$ use of a thioester also aides soft enolization in general, because of its enhanced acidity ${ }^{7}$ relative to other simple carboxylate derivatives. ${ }^{8}$ Viewed in this way, deprotonation in citrate synthase may be thought of as a form of soft enolization that results from a productive combination of favorable thioester acidity and appropriate spatial orientation of both activating hydrogen bonding functionality to its carbonyl and a base to its $\alpha$-protons, such that proximityassisted intracomplex deprotonation can occur. We anticipated that by mimicking this mode of enolization, particularly with regard to intracomplex deprotonation, we would be able to develop a catalytic asymmetric approach to enolate-based $\alpha$-alkylation of monocarboxylate-derived substrates, which remains an unmet goal in the field of organic synthesis. Herein, we report our initial success through the development of a biomimetic catalytic asymmetric Mannich reaction ${ }^{9}$ of phenylacetic acid thioesters ${ }^{10,11}$ and sulfonylimines using cinchona alkaloid-based amino (thio)urea catalysts.

The basic design elements of the catalyst (1) we chose to focus on initially are shown in Scheme 1b. A urea or thiourea

(6) For a review of metal-mediated complex induced proximity effects in deprotonation, see: Whisler, M. C.; MacNeil, S.; Snieckus, V.; Beak, P. Angew. Chem., Int. Ed. 2004, 43, 2206-2225.

(7) Bordwell, F. G.; Fried, H. E. J. Org. Chem. 1991, 56, 4218-4223.

(8) In other studies thioesters were shown to be well-suited to soft enolization, compared to oxoesters and amides (see ref $2 \mathrm{~d}$ ).

(9) For reviews of organocatalytic Mannich reactions see: Jingjun, M.; Ning, L.; Qiuhua, W.; Xin, Z.; Xiaohuan, Z.; Chun, W. Prog. Chem. 2008 20, 76-86. Ting, A.; Schaus, S. E. Eur. J. Org. Chem. 2007, 5797-5815.

(10) For examples of thioesters in organocatalysis, see: (a) Alonso, D. A.; Kitagaki, S.; Utsumi, N.; Barbas, C. F., III Angew. Chem., Int. Ed. 2008 47, 4588-4591. (b) Utsumi, N.; Kitagaki, S.; Barbas, C. F., III Org. Lett. 2008, 10, 3405-3408. For Malonic acid half-thioesters, see: (c) Lubkoll, J.; Wennemers, H. Angew. Chem., Int. Ed. 2007, 46, 6841-6844. (d) Ricci, A.; Petterson, D.; Bernardi, L.; Fini, F.; Fochi, M.; Herrera, R. P.; Sgarzani, V. Adv. Synth. Catal. 2007, 349, 1037-1040.

(11) For a review of thioesters in metal-mediated Mannich reactions see: Benaglia, M.; Cinquini, M.; Cozzi, F. Eur. J. Org. Chem. 2000, 563572. would provide the activating hydrogen bonding interaction. This would be connected to an amine such that the thioester $\alpha$-protons would be positioned in proximity to the base in the bound state, thus enabling intracomplex deprotonation $(\mathbf{3} \rightarrow \mathbf{4})$. An amine was chosen over a carboxylate as it would be both more strongly basic in this application and would lead to a relatively stable Zwitterionic ammonium enolate (4), ${ }^{12,13}$ further facilitating deprotonation. Reaction of the enolate with imine $\mathbf{5}$, followed by proton transfer, would then liberate the addition product (7) and regenerate the catalyst.

While the present study was underway, two reports ${ }^{10 a, b}$ describing intermolecular amine catalyzed deprotonation of $\alpha$-aryl $S$-trifluoroethyl thioesters (cf. $\mathbf{8} \rightarrow \mathbf{9} \rightarrow \mathbf{1 0}$, Scheme 2)

Scheme 2. Intermolecular Amine-Promoted Deprotonation

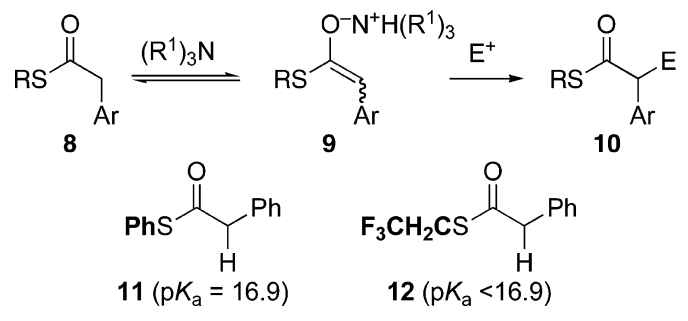

appeared. As part of these studies, the authors identified a functional $\mathrm{p} K_{\mathrm{a}}$ barrier of between 16-17 units for enolate precursors, above which simple equilibrium based deprotonation should not be feasible. ${ }^{10 a}$ This suggests that use of simple $S$-aryl or $S$-alkyl thioester derivatives of phenyl acetic acid ( $\mathrm{p} K_{\mathrm{a}} \geq 16.9$, cf. 11, Scheme 2), would not be practical in the context of equilibrium-based deprotonation using an amine catalyst alone. To overcome this limitation, more strongly acidic $\alpha$-aryl $S$-trifluoroethyl thioesters $\left(\mathrm{p} K_{\mathrm{a}}<16.9\right.$, cf. 12) were employed, which indeed enabled amine catalyzed additions. Unfortunately, augmenting reactivity by relying only on electronic activation of the thioester is inherently limited. At some point, as the thiol component of the thioester is made increasingly electron withdrawing, competing reactions such as ketene formation and acyl transfer will likely arise, precluding this approach as a general enolization technique.

In contrast to this approach, our proposed method of achieving the additional activation needed for enolization uses a combination of hydrogen bonding and proximity effects $^{5 \mathrm{~b}, \mathrm{~d}}$ to enable intracomplex soft enolization $(\mathbf{3} \rightarrow \mathbf{4}$; Scheme 1b). Not only should this facilitate deprotonation kinetically relative to intermolecular processes, but the enolate that forms should also be more stable thermodynamically, due to the cooperative internal stabilization of the hydrogen bonding and resulting ammonium moieties. Consequently, the ability to use enolate precursors less acidic

(12) Recent theoretical studies support the involvement of an enolate intermediate. See: Yalalov, D. A.; Tsogoeva, S. B.; Shubina, T. E.; Martynova, I. M.; Clark, T. Angew. Chem., Int. Ed 2008, 47, 6624-6628.

(13) Whether enolate stabilization is the result of a strong hydrogen bond or an ionic bond is uncertain. 
than $\alpha$-aryl $S$-trifluoroethyl thioesters should be possible, thereby opening the door to the development of a general mode of enolization-based organocatalysis of monocarboxylate derivatives.

The general structure of the catalyst (1) we required for our work is well-known in the context of bifunctional catalysts, which have been used to facilitate a variety of transformations. ${ }^{14}$ While those reactions proceed in mechanistically different ways not relying on proximity assisted enolization, the catalysts employed provided us with a starting point for our own studies. Thus, we began our investigations into the development of a biomimetic Mannich reaction by combining sulfonylimine $\mathbf{1 3}$ and $S$-phenyl thioester 11 in toluene, in the presence of $10 \mathrm{~mol} \%$ of known cinchona-derived amino thiourea $14^{15}$ (Table 1 , entry 1 ). We

Table 1. Survey of Conditions for the Biomimetic Mannich Reaction

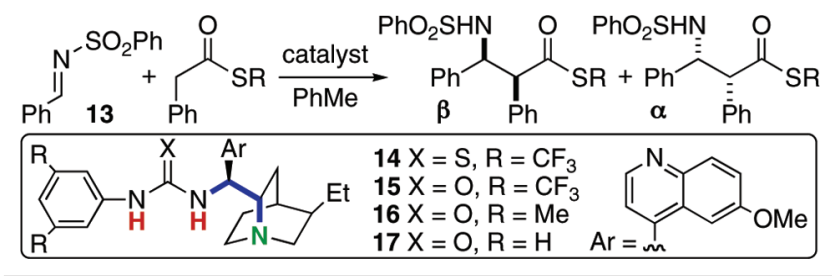

\begin{tabular}{|c|c|c|c|c|c|c|c|}
\hline \multirow[b]{2}{*}{ entry } & \multirow{2}{*}{$\begin{array}{c}\text { thioester } \\
(\mathrm{R})\end{array}$} & \multirow[b]{2}{*}{ cat. } & \multicolumn{3}{|c|}{ time } & \multicolumn{2}{|c|}{ conv } \\
\hline & & & mol \% & (h) & syn:anti & $\operatorname{er}(\beta: \alpha)$ & $\%$ \\
\hline 1 & $11(\mathrm{Ph})$ & 14 & 10 & 12 & $93: 7$ & $44: 56$ & 86 \\
\hline 2 & $18\left(4-\mathrm{NO}_{2}-\mathrm{C}_{6} \mathrm{H}_{4}\right)$ & 14 & 10 & 12 & $95: 5$ & $45: 55$ & 74 \\
\hline 3 & $19\left(4-\mathrm{OMe}-\mathrm{C}_{6} \mathrm{H}_{4}\right)$ & 14 & 10 & 12 & $93: 7$ & $50: 50$ & 71 \\
\hline 4 & $\mathbf{2 0}(\mathrm{Et})$ & 14 & 10 & 12 & 91:9 & $78: 22$ & 54 \\
\hline 5 & $12\left(\mathrm{CH}_{2} \mathrm{CF}_{3}\right)$ & 14 & 10 & 12 & $96: 4$ & $65: 35$ & 98 \\
\hline 6 & 12 & 14 & 5 & 3 & $96: 4$ & $66: 34$ & 95 \\
\hline 7 & 20 & 15 & 10 & 12 & $92: 8$ & $82: 18$ & 48 \\
\hline 8 & 12 & 15 & 5 & 3 & $96: 4$ & $71: 29$ & 93 \\
\hline 9 & 20 & 16 & 10 & 12 & $91: 9$ & $81: 19$ & 49 \\
\hline 10 & 12 & 16 & 5 & 3 & $92: 8$ & $71: 29$ & 98 \\
\hline 11 & 20 & 17 & 10 & 12 & $92: 8$ & $86: 14$ & 51 \\
\hline 12 & 12 & 17 & 5 & 3 & $97: 3$ & $81: 19$ & 88 \\
\hline
\end{tabular}

were pleased to find that the desired Mannich reaction did proceed in very good yield. ${ }^{16}$ Unfortunately, while the syn: anti selectivity was excellent, the reaction exhibited poor enantioselectivity. Variation of the thioester across a range of electron rich and deficient systems (entries 2-5) had little impact on diastereoselectivity, but significantly affected the

(14) See for example: (a) Andres, J. M.; Manzano, R.; Pedrosa, R Chemistry 2008, 14, 5116-5119. (b) Tan, K. L.; Jacobsen, E. N. Angew. Chem., Int. Ed. 2007, 46, 1315-1317. (c) Lubkoll, J.; Wennemers, H. Angew. Chem., Int. Ed. 2007, 46, 6841-6844. (d) Song, J.; Wang, Y.; Deng, L. J. Am. Chem. Soc. 2006, 128, 6048-6049. (e) Inokuma, T.; Hoashi, Y.; Takemoto, Y. J. Am. Chem. Soc. 2006, 128, 9413-9419. (f) Okino, T.; Hoashi, Y.; Furukawa, T.; Xu, X.; Takemoto, Y. J. Am. Chem. Soc. 2005, 127, 119-125. (g) Wang, J.; Li, H.; Yu, X.; Zu, L.; Wang, W. Org. Lett. 2005, 7, 4293-4296. (h) Wang, J.; Li, H.; Duan, W.; Zu, L.; Wang, W. Org. Lett. 2005, 7, 4713-4716. (i) McCooey, S. H.; Connon, S. J. Angew. Chem., Int. Ed. 2005, 44, 6367-6370. (j) Song, J.; Ye, J.; Dixon, D. J.; Hynes, P. S. Chem. Commun. 2005, 4481-4483. (k) Okino, T.; Hoashi, Y.; Takemoto, Y. J. Am. Chem. Soc. 2003, 125, 12672-12673.

(15) Connon, S. J. Chem. Commun. 2008, 2499-2510. Vakulya, B. Varga, S.; Csámpai, A.; Soós, T. Org. Lett. 2005, 7, 1967-1969.

(16) A similar experiment with the analogous oxoester (phenyl acetic acid phenyl ester) gave only recovered starting material after $36 \mathrm{~h}$. enantiomeric ratio, with the aliphatic thioesters (20 and 12) reacting enantioselectively (entries 4 and 5). Of these, the simple $S$-ethyl thioester $\mathbf{2 0}$ gave the best asymmetric induction. Further examination revealed that catalyst loading could be reduced to $5 \mathrm{~mol} \%$, and that the reaction was complete within $3 \mathrm{~h}$ in the case of $\mathbf{1 2}$ (entry 6), but not $\mathbf{2 0}$.

To improve asymmetric induction we examined urea catalyst 15 (Table 1). Although typically less effective than their thiourea analogues ${ }^{17}$ due to reduced hydrogen bonding capabilities, ${ }^{18}$ urea catalysts have been reported to possess superior anion stabilizing properties in some cases. ${ }^{19}$ In addition, Wennemers has shown that enolates formed by decarboxylation of malonic acid half thioesters undergo conjugate addition to nitroolefins with higher enantioselectivity when a urea rather than a thiourea cinchona-based catalyst is used. ${ }^{10 \mathrm{c}}$ Indeed, the enantioselectivity of the Mannich reaction between sulfonylimine 13 and both thioester $\mathbf{1 2}$ and $\mathbf{2 0}$ did increase somewhat with the use of urea catalyst 15 (entries 7 and 8). To further improve the enantioselectivity we conducted a cursory examination of the effect of the aniline component of the catalyst using $\mathbf{1 6}$ and 17 (entries 9-12). Interestingly, no difference was found between catalyst $\mathbf{1 5}$ and 16, suggesting that the electronic properties of the anilinyl group may be unimportant to asymmetric induction. In contrast, the enantioselectivity improved when the larger $\mathrm{CF}_{3}$ and methyl groups were replaced by hydrogen (17), implying that the steric properties of the aniline system are relevant in this regard.

Using catalyst $\mathbf{1 7}$, the scope of the reaction with various sulfonylimines was tested (Table 2). Both electron rich and

Table 2. Biomimetic Mannich Reaction with Various Sulfonylimines

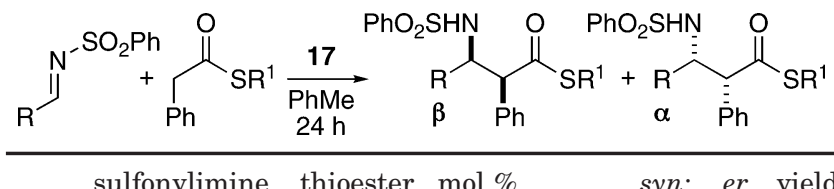

\begin{tabular}{|c|c|c|c|c|c|c|}
\hline entry & (R) & $\left(\mathrm{R}^{1}\right)$ & 17 & product & $\operatorname{anti}(\beta: \alpha)$ & $\%$ \\
\hline 1 & $13(\mathrm{Ph})$ & 20 (Et) & 20 & 25 & $95: 5 \quad 87: 13$ & 77 \\
\hline 2 & 13 & $12\left(\mathrm{CH}_{2} \mathrm{CF}_{3}\right)$ & 5 & 26 & $93: 781: 19$ & 95 \\
\hline 3 & 21 (furanyl) & 20 & 20 & 27 & $92: 8 \quad 76: 24$ & 66 \\
\hline 4 & 21 & 12 & 5 & 28 & 92:8 73:27 & 94 \\
\hline 5 & $22\left(4-\mathrm{Cl}-\mathrm{C}_{6} \mathrm{H}_{4}\right)$ & 20 & 20 & 29 & $93: 785: 15$ & 73 \\
\hline 6 & 22 & 12 & 5 & 30 & 91:9 74:26 & 90 \\
\hline 7 & $23\left(4-\mathrm{OMe}-\mathrm{C}_{6} \mathrm{H}_{4}\right)$ & 20 & 20 & 31 & $93: 784: 16$ & 41 \\
\hline 8 & 23 & 12 & 5 & 32 & $83: 17$ 76:24 & 50 \\
\hline 9 & $24\left(2-\mathrm{Me}-\mathrm{C}_{6} \mathrm{H}_{4}\right)$ & 20 & 20 & 33 & $98: 2 \quad 88: 12$ & 78 \\
\hline 10 & 24 & 12 & 5 & 34 & $97: 3 \quad 66: 34$ & 85 \\
\hline
\end{tabular}

electron deficient systems reacted effectively. While the reactions with $S$-trifluoroethyl thioester 12 could be conducted using less catalyst and were consistently more rapid

(17) Doyle, A. G.; Jacobsen, E. N. Chem. Rev. 2007, 107, 5713-5743.

(18) Fan, E.; Van Arman, S. A.; Kincaid, S.; Hamilton, A. D. J. Am. Chem. Soc. 1993, 115, 369-370.

(19) See for example: Maher, D. J.; Connon, S. J. Tetrahedron Lett. 2004, 45, 1301-1305. Nam, K. C.; Kang, S. O.; Ko, S. W. Bull. Korean Chem. Soc. 1999, 20, 953-956. Scheerder, J.; Engbersen, J. F. J.; Casnati, A.; Ungaro, R.; Reinhoudt, D. N. J. Org. Chem. 1995, 60, 6448-6454. 
and higher yielding, asymmetric induction was uniformly better with $S$-ethyl thioester 20. ${ }^{20}$

As shown above, despite being significantly less acidic than $S$-trifluoroethyl thioester $\mathbf{1 2}, S$-ethyl thioester $\mathbf{2 0}$ readily underwent the desired Mannich addition using catalysts 14-17. While the $\mathrm{p} K_{\mathrm{a}}$ values of compounds 20 and $\mathbf{1 2}$ have not been reported, their differential acidity can be estimated from the known ${ }^{6,21} \mathrm{p} K_{\mathrm{a}}$ of $\mathbf{1 1}, \mathbf{3 5}$ and $\mathbf{3 6}$ (Figure 1), along

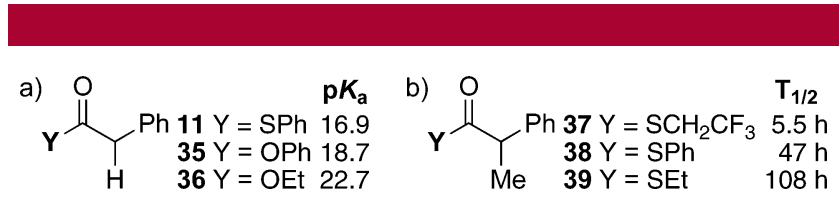

Figure 1. (a) Acidity of various phenylacetic acid derivatives. (b) $\mathrm{H} / \mathrm{D}$ exchange rates $\left(\mathrm{Et}_{3} \mathrm{~N}, \mathrm{CD}_{3} \mathrm{OD}\right.$, toluene- $\left.d_{8}\right)$.

with the rate of $\mathrm{H} / \mathrm{D}$-exchange of the related $\alpha$-phenyl propionate derivatives $37-39 .^{22}$ These data indicate that $O$-ethyl ester $\mathbf{3 6}$ is less acidic than $O$-phenyl ester $\mathbf{3 5}$ by 4 units, and that the half-life for $\mathrm{H} / \mathrm{D}$ exchange of $S$ trifluoroethyl thioester $37\left(\mathrm{~T}_{1 / 2}=5.5 \mathrm{~h}\right)$ is considerably less than that of the corresponding $S$-phenyl thioester $\left(\mathbf{3 8} ; \mathrm{T}_{1 / 2}\right.$ $=47 \mathrm{~h}$ ). Moreover, the $\mathrm{p} K_{\mathrm{a}}$ of $\mathbf{1 1}$ and $\mathbf{3 8}$ is expected to be similar. On this basis, it is reasonable to assume that the $\mathrm{p} K_{\mathrm{a}}$ difference between $S$-trifluoroethyl thioester $\mathbf{1 2}$ and $S$-ethyl thioester 20 is at least approximately 4 units. As such, the effective $\mathrm{p} K_{\mathrm{a}}$ barrier of the present catalytic method is estimated to be $\geq 20.9$ units $(16.9+4)$, which is well above the range of 16-17 that has been estimated ${ }^{10 a}$ for simple intermolecular amine catalyzed enolization. Significantly, this $\mathrm{p} K_{\mathrm{a}}$ barrier is not that far beyond the acidity range of simple thioesters.

We next tested the importance of proximity effects in the Mannich addition reaction (Figure 2). To do so, thioester 12 and sulfonylimine 13 were combined in toluene- $d_{8}$ along with: (1) catalyst 17, (2) 40, (3) 41, and (4) 41 plus 1,3diphenyl urea, and the reactions were monitored by ${ }^{1} \mathrm{H}$ NMR. $\mathbf{4 0}$ is structurally similar to catalyst $\mathbf{1 7}$ but is incapable of hydrogen bonding. The transformation employing $\mathbf{4 0}$ showed only a trace of product after $350 \mathrm{~min}$, by which time the reaction employing 17 was essentially complete. Compound 41 provided a second control offering similar steric bulk around the amine as found in $\mathbf{1 7}$, which would also not be capable of hydrogen bonding to the thioester carbonyl. Again, only a trace of product was formed with this base. The combination of $\mathbf{4 1}$ and 1,3-diphenyl urea showed little to no increase in reaction rate over $\mathbf{4 1}$ alone. The substantial increase in the rate of the transformation with $\mathbf{1 7}$ compared to the other systems analyzed supports the notion of proximity-assisted deprotonation.

(20) The lower yields for $\mathbf{2 0}$ resulted from incomplete conversion.

(21) Bordwell, F. G.; Fried, H. E. J. Org. Chem. 1981, 46, 4327-4331.

(22) Um, P. J.; Drueckhammer, D. G. J. Am. Chem. Soc. 1998, 120, $5605-5610$.

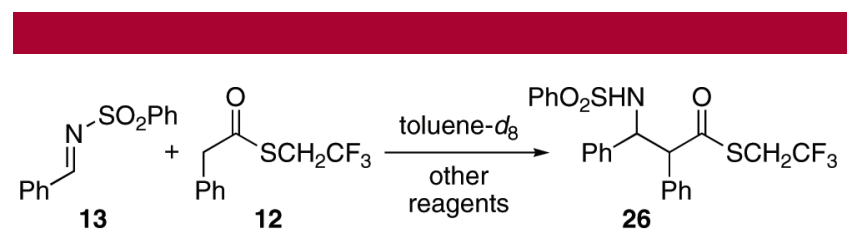

$$
\text { other reagents: = = } \mathbf{1 7}(5 \mathrm{~mol} \%) ;=\mathbf{~ = ~} \mathbf{4 0}(5 \mathrm{~mol} \%) ;-\mathbf{4 1}(5 \mathrm{~mol} \%) \text {; }
$$$$
\Delta=\mathbf{4 1}(5 \mathrm{~mol} \%)+1,3 \text {-diphenyl urea }(5 \mathrm{~mol} \%)
$$
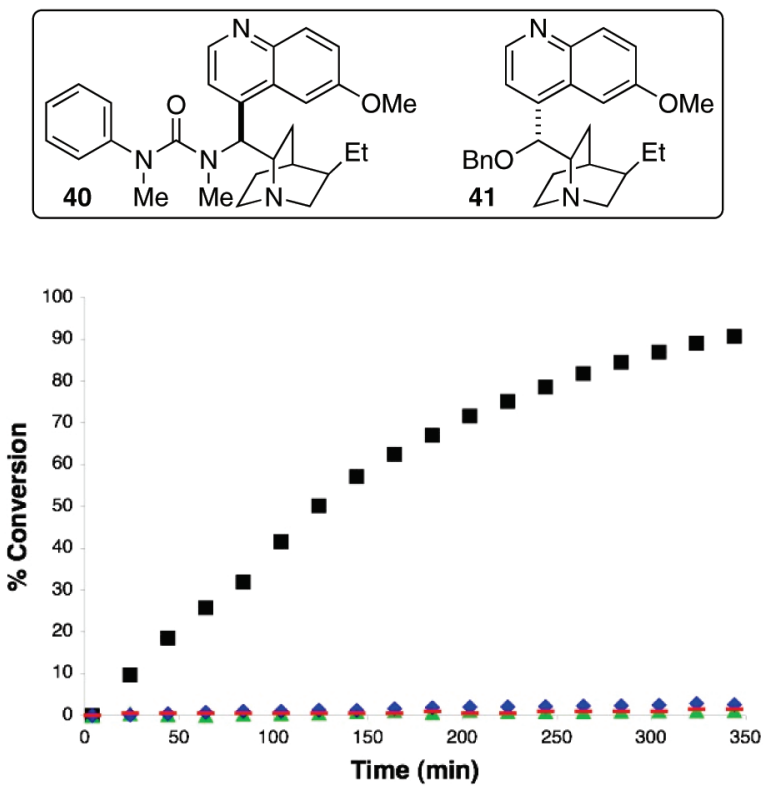

Figure 2. Evidence of proximity-assisted soft enolization (black square $=17$; red dash $=40$; blue diamond $=41$; green triangle $=$ $41+$ 1,3-diphenyl urea).

In conclusion, we have developed the first organocatalytic Mannich reaction based on proximity-assisted intracomplex soft enolization of thioesters using simple derivatives of known cinchona alkaloid-based catalysts. Significantly, the cooperative mode of enolization that functions in this case allows thioesters over a range of acidity to react efficiently. The functional $\mathrm{p} K_{\mathrm{a}}$ barrier associated with this method has been estimated to be $\geq 21$ units, suggesting its potential in terms of developing a general enolization-based organocatalytic strategy applicable to simple monocarboxylic acid derivatives. Mechanistic studies of this transformation are underway, as are studies on the use of different electrophiles and nucleophiles and the exploration and development of improved catalysts.

Acknowledgment. M.C.K. holds a Burroughs-Wellcome fellowship (Department of Chemistry, Duke University); M.R.G. is supported by the Pharmacological Sciences Training Program (Duke University). This work was supported by Duke University and NCBC (2008-IDG-1010).

Supporting Information Available: Experimental procedures and analytical data for all new compounds. This material is available free of charge via the Internet at http://pubs.acs.org.

OL101152B 